\title{
UMA BREVE REFLEXÃO DO PERCURSO DAS POLÍTICAS PÚBLICAS EDUCACIONAIS NO BRASIL: EM FOCO A FORMAÇÃO CONTINUADA
}

\author{
UNA BREVE REFLEXIÓN SOBRE EL CAMBIO DE LAS POLÍTICAS DE LA \\ EDUCACIÓN PÚBLICA EM BRASIL: ENFOCADA A LA FORMACIÓN CONTINUA
}
A BRIEF REFLEXION ON EDUCATIONAL PUBLIC POLICIES' PATH IN BRAZIL: FOCUS ON CONTINUED EDUCATION

\author{
Valdirene Eliane Bailon de SOUZA ${ }^{1}$ \\ Rita Márcia Andrade Vaz de MELLO ${ }^{2}$
}

RESUMO: O presente estudo objetiva analisar o percurso das políticas públicas educacionais no Brasil e discuti-las para a formação continuada de professores, averiguando a intervenção do Banco Mundial (BM) nesse contexto. O procedimento metodológico se deu através da análise bibliográfica da literatura especializada, com abordagem qualitativa. Dessa maneira, almeja-se que a temática apresentada contribua para promover o debate acerca das políticas públicas, além de apontar as fragilidades da relação Estado e Sociedade, que por vezes tornam as políticas públicas apenas instrumentos de controle estatal e social. Conclui-se que a política educacional voltada para formação continuada de professores da educação básica só terá sentido quando democraticamente construída por uma identidade coletiva e não individual.

PALAVRAS-CHAVE: Políticas públicas educacionais. Formação continuada. Banco mundial.

RESUMEN: El presente estudio pretende analizar el cambio de las políticas de educación pública en Brasil y discutirlas para la formación continua de profesores, averiguando la intervención del Banco Mundial (BM) en este contexto. El procedimento metodológico se hizo a través del análisis cualitativo de bibliografía especializada. De esta manera se espera que la temática presentada contribuya a promover el debate sobre las políticas públicas, además de resaltar las debilidades de la relación Estado y Sociedad, que en ocasiones hacen que las políticas públicas no sean otra cosa que instrumentos de control estatal y social. Se concluye, que, una política educacional dirigida a la formación continua de los profesores de educación básica, solo tendrá sentido cuando sea democráticamente construida por un identidad colectiva y no individual.

PALABRAS CLAVE: Políticas públicas educacionales. Formación continua. Banco mundial.

\footnotetext{
1 Universidade Federal de Viçosa (UFV), Viçosa - MG - Brasil. Professora do Programa de Apoio aos Dirigentes Municipais de Educação (PRADIME). ORCID: <http://orcid.org/0000-0002-9855-4823>. E-mail: valdirene.goncalves@yahoo.com.br

${ }^{2}$ Universidade Federal de Viçosa (UFV), Viçosa - MG - Brasil. Professora do Departamento de Educação e Coordenadora de Cursos Lato Sensu. Pós-Doutora pela Université Paris Descartes (Sorbonne). ORCID: <http://orcid.org/0000-0002-7473-9559>. E-mail: ritamarciamello@gmail.com.br
} 
ABSTRACT: This study aims to analyze the route of educational public policies in Brazil and discuss them regarding continued teacher education, investigating the World Bank's intervention in this context. In such case, it aims that the theme presented contributes to promote public policies' debate, besides indicating the weaknesses of the relationship between State and Society, which sometimes only makes public policies an instrument of state and social control. It concludes that the educational policy focused on basic education teachers' continued training, will only make sense when democratically constructed by a collective identity not an individual one.

KEYWORDS: Educational public policies. Continued education. World bank.

\section{Introdução}

Atualmente a educação pública brasileira é transposta por vários problemas provenientes de uma sociedade capitalista, no entanto, é imprescindível entender sobre o contexto das políticas educacionais voltadas para formação continuada de professores, seus avanços e retrocessos no sistema educativo.

Para Gatti (2010), o surgimento de tantos tipos de formação e de políticas educacionais tem base histórica em condições emergentes na sociedade contemporânea, nos desafios colocados aos currículos e ao ensino, e nas dificuldades do dia-a-dia nos sistemas de ensino. Assim, as questões que envolvem a política educacional no Brasil, especificamente aquelas voltadas para formação continuada dos profissionais da educação, têm sido objeto de inúmeros estudos nas últimas décadas (MAINARDES, 2011).

Nesse sentido, ressalvamos nesse estudo a ideologia que fundamenta o Banco Mundial (BM), que de certa forma orienta e desenvolve políticas visando empreender uma sociedade que atenda aos seus interesses estratégicos. Neste cenário, o BM, apesar de ser um organismo financeiro internacional que se propõe ao financiamento de projetos e políticas para educação, não perde seu caráter explícito de agência financeira diretamente ligada aos interesses econômicos privados.

Percebemos a necessidade de uma compreensão mais ampla sobre a política educacional e sua relação na conjuntura da sociedade brasileira. Desta forma, a partir de uma análise bibliográfica da literatura, com abordagem qualitativa, realizamos um resgate histórico em assuntos que subsidiaram a pesquisa, através de leituras em livros, artigos científicos, planos, relatórios, projetos de lei, decretos, portarias, entre outros.

Para Ludke e André (1986), a análise documental constitui-se em valiosa fonte de informações sobre o objeto de estudo, pois revela aspectos ou complementa informações 
obtidas com a utilização de outras técnicas. Sendo uma fonte estável, os documentos podem ser consultados diversas vezes, o que possibilita a retirada de evidências que fundamentam afirmações e declarações do pesquisador. A respeito da análise bibliográfica, Gil (2006) apresenta que a principal vantagem reside no fato de permitir ao investigador a cobertura de uma gama de fenômenos muito mais ampla do que aquela que poderia pesquisar diretamente.

Os apontamentos e as reflexões expressas neste estudo se constituem, num primeiro momento, no embasamento teórico abordando as políticas públicas educacionais, e a intervenção de agentes internacionais, nesse caso específico, o Banco Mundial (BM). Em seguida, buscaremos apresentar as políticas públicas voltadas para a formação continuada dos profissionais da educação. E, nas Considerações Finais, procura-se mostrar, de forma crítica e reflexiva, o que se consideram pontos positivos e negativos das políticas, no tocante à melhoria da qualidade da educação por intermédio da formação continuada.

Assim, através desse artigo procuramos apresentar alguns caminhos possíveis para que os estudos sobre as políticas educacionais possam, além de apontar as fragilidades da relação Estado e Sociedade, que por vezes tornam as políticas públicas apenas instrumentos de controle estatal e social, também apreender a configuração que as mesmas assumem nos diferentes contextos em que são aplicadas.

\section{Breve apontamento sobre a política educacional e o Banco Mundial (BM)}

Consideramos importante salientar que as mudanças vivenciadas no período de 1990 na educação brasileira estão envoltas na evolução das LDBs e, especialmente, no uso de Políticas Públicas Educacionais voltadas para a construção de uma educação com qualidade. Abordaremos a seguir algumas expressões e opiniões sobre as políticas públicas educacionais na visão de alguns autores.

No cenário brasileiro, com ênfase para o período de 1990, a expressão Políticas Públicas Educacionais ganhou expressiva notoriedade. No entanto, tais políticas nem sempre trouxeram os resultados esperados, pois somente garantir o acesso à educação pública não significa que a mesma tenha qualidade e que, efetivamente, os usuários terão seus direitos respeitados (SETUBAL, 2012).

Diante deste aspecto, tem-se que as Políticas Públicas se voltam para o enfrentamento dos problemas existentes no cotidiano das escolas. Porém, somente o direcionamento destas para a educação não constitui uma forma de efetivamente auxiliar professores, crianças e adolescentes a um ensino de melhor qualidade, posto que existem outros pontos que também 
devem ser tratados a partir das Políticas Públicas, como os problemas de fome, drogas e a própria violência que vem se instalando nas escolas em todo o Brasil (QUADROS, 2008).

Quando discorremos sobre Políticas Públicas para educação, a abordagem em si, tratase da articulação de projetos que envolvem o Estado e a Sociedade, na busca pela construção de uma educação mais inclusiva e de melhor qualidade, ou seja, que resgate a construção da cidadania (GIRON, 2008). No entanto, nesse tocante, tem sido para a Educação que os principais organismos internacionais têm se voltado. Articular a educação à lógica de mercado é o esforço empreendido pelos projetos de reforma educacional para a Educação na contemporaneidade, empreendido e financiado por organismos internacionais como o Banco Mundial (BM).

A importância que o Banco Mundial (BM) vem desempenhando nos rumos das sociedades capitalistas dependentes alterou-lhe profundamente sua função histórica, como se pode observar na seguinte assertiva de Torres (1998, p. 126):

O Banco Mundial transformou-se, nos últimos anos, no organismo com maior visibilidade no panorama educativo global ocupando, em grande parte, o espaço tradicionalmente conferido a UNESCO (Organização das Nações Unidas para a Educação, a Ciência e a Cultura), a agência das Nações unidas especializada em educação. O Financiamento não é o único e o mais importante papel do BM em educação (representando apenas $0,5 \%$ da despesa total pelos países em desenvolvimento neste setor); o BM transformou-se na principal agência de assistência técnica em matéria de educação para os países em desenvolvimento e, ao mesmo tempo a fim de sustentar tal função técnica, em fonte e referencial importante de pesquisa educativa no âmbito mundial.

Para situarmos melhor segundo o exposto pelo autor, as reformas educacionais foram marcadas pela influência das agências multilaterais como o Banco Mundial (BM), a Organização das Nações Unidas para Educação, a Ciência e a Cultura (UNESCO), a Organização para a Cooperação e Desenvolvimento Econômico (OCDE), o Programa das Nações Unidas para o Desenvolvimento (PNUD), entre outros. Os documentos formulados por essas agências, além de prescrever as orientações a serem adotadas, também forjaram discurso justificador das reformas. "[...] tais agências produziram a reforma e exportaram também a tecnologia de como fazê-las” (SHIROMA; CAMPOS; GARCIA 2005, p. 430).

No Brasil, a intervenção dessas agências, sobretudo a do Banco Mundial (BM), decorreu mais da influência política junto aos governos por meio da imposição de temas prioritários, linhas de ação e de um enfoque economicista das políticas educacionais, do que 
dos recursos financeiros que são mobilizados para a implantação de projetos educacionais (HADDAD, 2008).

Em relação às recomendações do Banco Mundial $(\mathrm{BM})$ para a educação, elas são balizadas dentro de uma perspectiva economicista, e a educação passa a ser encarada como fator de eficiência dos serviços de ensino e de amparo social. Conforme Tommasi (2007), o caráter educativo é depreciado em favor de uma lógica de mercado, e a educação passa a ser considerada como um pilar estratégico para o desenvolvimento econômico mundial globalizado.

De acordo com o processo normativo, é importante salientar que a Lei de Diretrizes e Bases da Educação Brasileira (LDB 9394/96) é a legislação que regulamenta o sistema educacional (público ou privado) do Brasil (da educação básica ao ensino superior). Dessa forma, as Políticas educacionais no contexto brasileiro tiveram como fio condutor essas diretrizes, que assumiram um caráter de centralidade nas reformas educacionais brasileiras ocorridas durante o período de 1990 (BRASIL, 2005).

Para Freire (1998), tem-se que o sistema educativo adotado e as Políticas Públicas direcionadas para a educação são elementos que demonstram a preocupação do país com o seu futuro, pois somente o ensino público gratuito, inclusivo e de qualidade pode construir uma sociedade em que as diferenças socioculturais e socioeconômicas não sejam tão díspares.

O Banco Mundial (BM) desenvolve um papel estratégico na definição das políticas educacionais, atuando, conforme Leher (1998), como "Ministério Mundial da Educação", exportando pacotes de políticas educacionais aos países em desenvolvimento que sucumbem ao peso e aos interesses do capital internacional. Aqui, a educação restringe-se ao papel de reproduzir a força de trabalho para o capital, formar ideologicamente conforme os interesses dele e servir como segmento do mercado a ser explorado comercialmente pelo setor privado.

Soares (2007) evidencia que foi no período de 1980, com a crise do endividamento, que iniciou a atuação do Banco Mundial (BM) e do Fundo Monetário Internacional (FMI) na área da educação, propondo programas de estabilização e de ajuste da economia brasileira. Esta intervenção não foi só como base na formulação da política econômica interna, como também teve influências sobre o conjunto da legislação brasileira nos diversos âmbitos das políticas sociais.

\section{Contextualizando as políticas educacionais para formação continuada}


O ponto de referência que tomamos para olhar as políticas de formação inicial de professores é o papel da escola nas sociedades contemporâneas e, em decorrência, o papel dos professores nesse contexto. Compreendemos que a importância dos professores e gestores para a oferta de uma educação de qualidade para todos é amplamente reconhecida. Desse modo, a formação inicial e continuada, os planos de carreira, as condições de trabalho e a valorização desses profissionais, entre outros aspectos, ainda são desafios para as políticas educacionais no Brasil.

Primeiramente, se torna viável conhecer as políticas públicas em Educação desenvolvidas no Brasil pelo governo federal para fundamentação desse estudo. Para Azevedo (2003, p. 23), "política pública é tudo o que um governo faz e deixa de fazer, com todos os impactos de suas ações e de suas omissões", é uma condição exclusiva do governo no que se refere à formulação, deliberação, implementação e monitoramento.

Segundo Gatti (2010), tudo que possa oferecer oportunidade de conhecimento, reflexão, debate e trocas que favoreçam o aprimoramento profissional, em qualquer de seus ângulos, em qualquer nível, é considerado formação continuada. Assim, podemos afirmar que essa perspectiva é abrangente e inclui trocas diárias com os pares no cotidiano escolar, horas de trabalho coletivo na escola, reuniões pedagógicas, participação na gestão escolar, congressos, seminários, cursos de diversas naturezas e formatos, oferecidos pelas Secretarias de Educação ou outras instituições, e também pode ser buscada pelo próprio docente em lugares diversos. Além disso, as atividades podem ser oferecidas através de processos a distância, semipresenciais, presencias, entre outros.

Para Fusari e Rios (1995, p. 38), a formação continuada é entendida como “[...] o processo de desenvolvimento da competência dos educadores, aqueles que têm como oficio transmitir, criando e reproduzindo, o conhecimento histórico e socialmente construído por uma sociedade". Essa competência, definida pelos autores como saber fazer bem o que é necessário, desejado e possível no espaço de sua especialidade, não deve ser entendida como algo estático e sim como algo que se constrói pelos profissionais em sua práxis cotidiana.

Sobre essa perspectiva, a formação continuada de professores da Educação Básica em serviço tem sido contemplada em muitas reformas educacionais. Apesar disso, a realidade verificada, na grande maioria das instituições, é que os programas de formação pouco têm contribuído para que aconteçam mudanças significativas em sala de aula em relação à concepção de ensino-aprendizagem; à aprendizagem dos alunos e à coerência de um referencial teórico metodológico. 
Segundo as diretrizes do Plano Nacional de Educação (PNE), a formação continuada dos profissionais da educação pública deveria ser garantida pelas secretarias estaduais e municipais de educação, cuja atenção incluía a coordenação, o financiamento e a manutenção dos programas como ação permanente e a busca de parcerias com universidades e instituições de ensino superior. Mesmo com toda essa preocupação com a formação continuada, ainda é possível observar que existe no Brasil um quantitativo significativo de profissionais sem formação superior atuando no Ensino Fundamental em quase todo o país, e professores sem formação adequada atuando no Ensino Médio (CHAVES, 2012).

Uma das maiores críticas ao PDE recai sobre o fato de ser um plano de governo sem garantia de continuidade. Já de acordo com o MEC, o ponto forte desse plano é a formação de professores e a valorização dos profissionais da educação. Através desse apontamento e analisando brevemente essas questões, as políticas de formação de professores no Brasil empreendeu maiores esforços no sentido de viabilizar por todos os meios, presencial ou a distância, a elevação do nível de formação dos docentes da rede pública.

Vários autores têm discutido a formação continuada de professores, tais como: Nóvoa (1992); Fusari e Rios (1995); Candau (1999); Demo (2000); Ferreira (2000); Domite (2006); Gatti (2010); entre outros.

Para Demo (2000), os cursos de formação continuada de professores precisam ter como prioridade a aprendizagem do aluno, então, o professor precisa estudar, nos encontros de formação, teorias e práticas de aprendizagem, ou seja, é necessário aprender a pesquisar estratégias ativas que ajudem na construção e reconstrução de conhecimento. Para tanto, é necessário que haja continuidade no processo de formação, já que não é em um ou em alguns encontros que o professor irá desenvolver essas aprendizagens.

Atualmente há vários programas ${ }^{3}$ de formação continuada oferecidos pelo governo em parceria com o Ministério da Educação (MEC). Dentre os que estão vigentes no momento, podemos citar: o Programa Mais Educação, Programa de Formação Continuada de Professores na Educação Especial, Programa Nacional Escola de Gestores da Educação Básica, Programa Nacional de Formação Continuada em Tecnologia Educacional, entre outros.

De acordo com Domite (2006), vários modelos têm sido propostos para a formação de professores, entre os quais bem poucos voltados para a formação do professor (a) enquanto

3 Para saber mais sobre os Programas de Formação Continuada vigentes, basta acessar o link: http://portal.mec.gov.br/index.php?option=com_content\&id=15944:programas-do-mec-voltados-formacao-deprofessores. 
sujeito social de suas ações e, por isso, mais do tipo transmissivo e impositivo, outros já mais centrados nos tipos de processos de transformação e na própria dinâmica formativa.

De fato, nos últimos anos, as discussões em torno da formação continuada não têm colocado como prioridade a preparação do professor para o ensino dos conteúdos. Mas sim, como já dito, destacado a importância do professor como profissional reflexivo, que deve preocupar-se tanto com as necessidades emocionais e intelectuais dos educandos, assim, também com as funções sociais da educação, exercitando-se como colaborador político do projeto pedagógico educacional.

Ainda assim, mesmo em meio a essa diversidade de pontos de vista e embora os órgãos responsáveis pelo sistema educacional pareçam cientes de que a especialização e a atualização são determinantes para a transformação da qualidade do ensino, deparamo-nos com programas que se resumem a cursos inteiramente programados e estruturados a priori, antes dos formadores ou organizadores saberem quais grupos de profissionais serão formados.

Quando isso ocorre, como bem ressalta Nóvoa (1992), o professor é colocado no nível mais baixo da ordem epistemológica, sendo visto, e se comportando, muitas vezes, como executor de programas muito padronizados, que são preparados em níveis de organização escolar distantes do seu local de aplicação, tornando-se assim dependente de especialistas para solucionar problemas recorrentes em sua prática.

Por questionarmos e tentarmos compreender os problemas provenientes do âmbito escolar, principalmente, da relação professor-aluno, no qual programas são elaborados sem levar em conta a realidade, problemas, eficiências ou deficiências, é que ressalvamos a forma pela qual algumas instituições elaboram seu plano de ação diante dos cursos de formação continuada. Segundo Caldeira (1993), a maior parte dos conhecimentos que os professores "recebem" nos cursos são definidos de fora, o que explica a relação de exterioridade que os docentes estabelecem com eles.

Conforme o autor Candau (1996), os cursos de Formação Continuada de Professores devem reconhecer a necessidade de um profissional que se envolva com o cotidiano da escola e que possa intervir na construção e reconstrução dos processos que se desenvolvem nas instituições escolares.

Por consequência, é necessário que o profissional da educação possa refletir criticamente a respeito das demandas sociais, de sua função nesse contexto e da necessidade de formação contínua ao longo de sua carreira profissional, uma vez que entendemos a formação de professores a partir da ideia de continuidade, de incompletude. Porto (2000, p. 14), reforça este pressuposto ao afirmar que: 
A formação não se conclui, cada momento abre possibilidades para novos momentos de formação, assumindo um caráter de recomeço, renovação, inovação da realidade pessoal e profissional, tornando-se a prática, então, a mediadora da produção do conhecimento ancorado, mobilizado na experiência de vida do professor e em sua identidade, construindo-se, a partir desse entendimento, uma prática interativa e dialógica entre o individual e o coletivo.

Compreendemos e defendemos que formação continuada precisa ser um processo contínuo, permanente e integrado ao dia-a-dia dos professores e da própria instituição escolar. A educação escolar precisa de um profissional em constante processo de aprendizagem, um professor que repense, avalie e refaça o seu trabalho com leituras, pesquisas e troca de experiência. Por intermédio destas ações, ele vai questionando o próprio modo de proceder, reconstruindo permanentemente o seu fazer pedagógico.

Podemos notar que com o processo de globalização as políticas públicas estão mais a serviço da lógica do mercado do que voltadas ao atendimento das necessidades e demandas sociais, deixando de lado o compromisso com as camadas populares, reflexo do sistema produtivo e de acumulação, caracterizado pela privatização e exclusão social. Segundo Saviani (1987, p. 1):

Considerar a política educacional como dimensão da política social significa, fundamentalmente, considerar a política educacional como tendo compromisso com as camadas populares, isto é, com aquelas camadas que não se beneficiam diretamente do desenvolvimento econômico. Nesse sentido, me parece que a questão central diz respeito ao desenvolvimento intelectual das massas [...] encaminho as discussões entre a educação e as chamadas políticas especiais [...] um desenvolvimento intelectual satisfatório a criança necessita de algumas pré-condições, como por exemplo, a alimentação, ambiente familiar adequado e, assim por diante. E, aí, então, são acionadas as políticas especiais, como por exemplo a merenda escolar.

Ao discorrer sobre a qualidade dos professores da educação básica, também se está indiretamente referindo aos gestores de escolas que de origem são professores. Não é de hoje que pesquisas apontam que as formas de atuação dos gestores escolares estão relacionadas às condições de um funcionamento mais efetivo das escolas (CASTRO, 2006). Isso mostra que a formação inicial dos docentes tem implicações amplas para as escolas, na medida em que também esses profissionais poderão ser convocados a exercer a função de coordenadores pedagógicos, supervisores educacionais, gestores, ou outras atividades nas redes de ensino.

Entre as medidas do governo federal que ocorrem nessa direção, uma das mais importantes pelas dimensões que assume é a criação da Universidade Aberta do Brasil 
$(\mathrm{UAB})^{4}$, por meio do Decreto ${ }^{\circ}$ 5.800/2006, sob a responsabilidade da Diretoria de Educação a Distância, ligada à Coordenadoria de Aperfeiçoamento de Pessoal de Nível Superior (Capes), em parceria com a Secretaria de Educação a Distância do MEC. Seu objetivo é promover a formação inicial e continuada de professores, utilizando metodologias de Educação a Distância (EaD) (BRASIL, 2005).

A instituição do sistema UAB ocorreu logo após a promulgação do Decreto $\mathrm{n}^{\circ}$ $5.622 / 2005$, que conferiu novo ordenamento legal à $\mathrm{EaD}$, equiparando os cursos nessa modalidade aos cursos presenciais e estabelecendo a equivalência de diplomas e certificados na educação superior. A medida legal assenta-se no pressuposto de que a EaD constitui a iniciativa de maior alcance para enfrentar as novas demandas do número de egressos do ensino médio e de formação docente, estimada, em 2002, em 875 mil vagas no ensino superior (GATTI; BARRETTO, 2009).

A institucionalização da formação superior de docentes a distância, concebida sob a forma de educação continuada que utiliza essas novas tecnologias, teve impulso na UAB por meio do Programa Pró-Licenciatura, criado pelo MEC, em 2005, e dirigido a professores em serviço sem formação em nível superior ou atuando fora da área de sua formação. A oferta de programas de formação inicial nesses moldes representou uma ruptura com os programas de curta duração e com o caráter mercadológico que informava muitos deles (FREITAS, 2007).

A UAB tornou-se um dos principais instrumentos de execução das políticas de formação em nível superior do MEC, ao lado do Programa de Apoio aos Planos de Reestruturação e Expansão das Universidades Federais (Reuni), que se propõe a criar condições de ampliação do acesso aos cursos de graduação públicos e de permanência neles, mediante melhor aproveitamento da infraestrutura física e de recursos humanos existentes nas universidades.

Conforme aponta Costa (2007), a UAB foi instituída pelo MEC, em parceria com a Secretaria de Educação Continuada, Alfabetização, Diversidade e Inclusão (Secadi) e a coordenação da Capes, e com a participação de IFES $^{5}$ pertencentes esta rede, para a oferta de cursos semipresenciais de formação continuada e a elaboração de material didático específico.

As propostas dos cursos pelas IFES são orientadas por critérios estabelecidos em edital do MEC, que define objetivos, público-beneficiário, carga horária, organização dos módulos,

4 A UAB é um sistema integrado por instituições Federais de ensino superior (IFES) que oferece cursos dirigidos preferencialmente a segmentos da população que têm dificuldade de acesso à formação superior. A prioridade é de atendimento aos professores que atuam na educação básica, seguidos de dirigentes, gestores e trabalhadores da educação básica dos estados, do Distrito Federal e dos municípios.

${ }^{5}$ Instituto Federal de Ensino Superior. 
conteúdo e proposta metodológica. Há indicação clara de que a metodologia dos cursos deve atender ao desenvolvimento de um percurso de aprendizagem que se inicia com o diagnóstico da realidade na qual os cursistas vivem, seguindo-se de aprofundamento teórico-conceitual das temáticas mencionadas, até a conclusão de um projeto de intervenção local, que é o trabalho final de curso. Não se trata ainda, em decorrência da dimensão temporal dos cursos, da implementação desses projetos no decorrer dos cursos, com monitoramento, apoio, orientação dos formadores dos cursos, como sugerem as experiências mais bem-sucedidas de formação docente (BRASIL, 2005).

Nessa perspectiva, analisando dentre os vários aspectos acima citados, é possível observar a necessidade de valorização da criticidade nos cursos de formação, ou seja, torna-se imprescindível realizar uma formação focada em práticas formativas que ajudem o professor a desenvolver uma postura crítica a respeito de sua prática pedagógica, da realidade social, tendo como objetivo analisar criticamente o contex to em que atua.

\section{Considerações finais}

Este estudo teve como foco refletir sobre as políticas educacionais em geral e buscar entender os mecanismos que movimentam o sistema; intervir nesse contexto é fundamental na busca de outro tipo de sociedade que tenha um projeto educativo centrado no ser humano e na valorização de suas potencialidades.

O Banco Mundial (BM) surge nesse cenário das políticas educacionais, como forma de superar a fragilidade da educação. A ênfase dada pelo banco à formação continuada é decorrente de uma análise que privilegia aspectos econômicos, baseada em estudos de custobenefício, em que a formação docente é pensada em termos da melhor forma de se produzir um profissional competente tecnicamente. Nessa lógica, a educação em serviço apresenta-se como forma mais barata e mais eficiente de formar profissionais para a educação.

O investimento na educação continuada é proposto pelo banco na perspectiva de melhorar o desempenho docente mediante maior domínio que o professor venha a ter dos conteúdos das disciplinas e de estratégias pedagógicas para ministrá-las, instrumentalizando o docente para seguir diretrizes e normas curriculares. A competência pensada em termos de autonomia, que exige formação técnica e política, faz parte da agenda daqueles comprometidos com uma educação fundada na ideia de emancipação.

Nesse sentido, diante das reflexões aqui explicitadas, concordamos com Tedesco (2010), quando este afirma que na educação se tem elaborado muitas soluções para problemas 
que não são concretos e se continua sem soluções para os problemas concretos das redes de ensino. Segundo o autor, o problema educacional central e essencial não é propriamente a descentralização, a autonomia, as escolas, a gestão, as questões que se mostram prioritárias nas reflexões sobre política educacional. Esses fatores mudam seus sentidos, conforme interesses e movimentos histórico-sociais diversos.

Entendemos que a formação continuada deve estar vinculada, articulada ao âmbito do trabalho docente e tendo a escola como lócus de formação. É necessário que o professor vivencie a teoria e a prática, e que estes sejam subsidiados por um referencial teóricometodológico crítico, que ao ser desenvolvido em sala de aula dê prioridade à aprendizagem do aluno e ao crescimento profissional do professor.

Concluindo, pode-se afirmar que a política educacional só terá sentido quando democraticamente construída por uma identidade coletiva e não individual. O Estado é um dos principais lugares da política e um dos principais atores políticos. Em vista disso, corroboramos com as afirmativas de Mainardes (2011), ao apontar que as novas relações entre Estado e Sociedade são definidas para a conformação social, tendo na Educação instrumento hegemônico de legitimação das relações sociais vigentes.

\section{REFERÊNCIAS}

AZEVEDO, S. de. Políticas públicas: discutindo modelos e alguns problemas de implementação. In: SANTOS JUNIOR, Orlando A. dos et al. Políticas públicas e gestão local: programa interdisciplinar de capacitação de conselheiros municipais. Rio de Janeiro, FASE, 2003.

BRASIL. Orientações Gerais. Rede Nacional de Formação Continuada de Professores de Educação Básica. Brasília: MEC/SEB, 2005.

CALDEIRA, A. M. S. La práctica docente cotidiana de una maestra y el proceso de apropiación y construcción de su saber. 1993. 347f. Tese (Doutorado), Universidade de Barcelona, Barcelona, 1993.

CASTRO, C. M. A escola que os brasileiros frequentaram em 1985. Brasília: Ipea, 2006.

CANDAU, V. M. F. Formação Continuada de professores: tendências atuais. In: REALI, A. M. de M. R.; MIZUKAMI, M. da G. N. (Orgs.). Formação de professores: tendências atuais. São Carlos: EDUFSCar, 1996. p. 139-152.

CHAVES, S. D. Políticas Públicas de formação continuada de professores: a experiência do município de Itaguaí. 2012. Dissertação (Mestrado em Educação), Universidade Estácio de Sá, 2012. 
COSTA. C. J. Modelos de Educação Superior a Distância e Implementação da Universidade Aberta do Brasil. Revista Brasileira de Informática Educativa, v. 15, n. 2, 2007.

DEMO, P. Desafios modernos da educação. 10. ed. Petrópolis: Vozes, 2000. 272 p.

DOMITE, M. C. C. Formação de professores e Etnomatemática: compreendendo para pedir mudanças. In: III SIPEM - Seminário Internacional de Pesquisas em Educação Matemática, Águas de Lindóia, 2006.

FREIRE, P. Pedagogia da autonomia: saberes necessários à prática educativa. São Paulo: Paz e Terra, 1998.

FREITAS, H. C. L. A (nova) política de formação de professores: a prioridade postergada. Educação \& Sociedade, Campinas, v. 28, n. 100, Especial, p. 1203-1230, out. 2007.

FUSARI, J. C.; RIOS, T. A. Formação continuada dos profissionais do ensino. In: Caderno Cedes, Campinas, n. 36, p. 37-46, 1995.

GATTI, B. A. Formação de professores no Brasil: características e problemas. Educação e Sociedade, Campinas, v. 31, n. 113, p. 1355-1379, out./dez. 2010.

GATTI, B. A; BARRETTO, E. S. de S. Professores do Brasil: impasses e desafios. Brasília: UNESCO, 2009. Disponível em: http://unesdoc. unesco.org/images/0018/001846/184682por.pdf. Acesso em: 18 jul. 2015.

GIL, A. C. Métodos e técnicas de pesquisa social. 5. ed. São Paulo: Atlas, 2006.

GIRON, G. R. Desafios políticos para educação. Travessias, Cascavel/PR, v. 2, n. 1, p. 1-13, jan./abr. 2008.

HADDAD, S. (orgs.) O Banco Mundial e as políticas educacionais. São Paulo: Cortez, 2008. p. 195-227.

LEHER, R. Da ideologia do desenvolvimento à ideologia da globalização: a educação como estratégia do Banco Mundial para "alívio" da pobreza. 1998. Tese (Doutorado em Educação), São Paulo/SP: FEUSP, 1998.

LÜDKE, M.; ANDRÉ, M. Pesquisa em educação: abordagens qualitativas. São Paulo: EPU, 1986. 99 p.

MAINARDES, J; FERREIRA, M. S.; TELLO, C. Análise de políticas: fundamentos e principais debates teórico-metodológicos. In: Ball, S. J.; Mainardes, J. (Org.). Políticas Educacionais: questões e dilemas. $1^{a}$ ed. São Paulo: Cortez, 2011, v., p. 143-172.

NÓVOA, A. Os professores e a sua formação. Lisboa: Publicações Dom Quixote, 1992.

OLIVEIRA, D. A. Educação básica: gestão do trabalho e da pobreza. Petropólis: Vozes, 2000. 
PORTO, Y. da S. Formação continuada: a prática pedagógica recorrente. In: MARIN, Alda J. (Org.). Formação continuada. Campinas, SP: Papirus, 2000. p. 11-37.

QUADROS, N. H. B. de. Políticas públicas voltadas para a qualidade da educação no ensino fundamental: inquietudes e provocações a partir do plano de desenvolvimento da educação. 2008. Dissertação (Mestrado em Educação). Passo Fundo-RS: Faculdade de Educação da Universidade de Passo Fundo, 2008.

SAVIANI, D. Política e Educação no Brasil: o papel do Congresso Nacional na Legislação do Ensino, São Paulo, Cortez, 1987.

SETUBAL, M. A. Com a palavra. Consulex. Ano XVI. N.382. 15 de dezembro de 2012.

SOARES, M. C. C. Banco Mundial: políticas e reformas. In: TOMMASI, Livia de.; WARDE, Mirian Jorge.; HADDAD, Sérgio (Org.). O Banco Mundial e as políticas educacionais. 5. ed. São Paulo: Cortez, 2007. p. 15-39.

SHIROMA, E. O.; CAMPOS, R. F.; GARCIA, R. M. C. Decifrar textos para compreender a política: subsídios teórico-metodológicos para análise de documentos. Perspectiva, Florianópolis, v. 23, n. 2, p.427-446, jul./dez.2005.

SHIROMA, E. O.; MORAES, M. C. M. de; EVANGELISTA, O. Política Educacional. $4^{\text {a }}$ ed. Rio de Janeiro: Lamparina, 2007.

TEDESCO, J. C. Presentación. In: OLIVEIRA, D. A. et al. Políticas educativas y territórios: modelos de articulación entre niveles de gobierno. Buenos Aires: UNESCO IIPE, 2010.

TOMMASI, L. de. Financiamentos do Banco Mundial no setor educacional brasileiro: os projetos em fase de implementação. IN: TOMMASI, Lívia de.; WARDE, Miriam Jorge; HADDAD, Sérgio (orgs.). O Banco Mundial e as políticas educacionais. 5. ed. São Paulo: Cortez, 2007.

TORRES, R. M. Melhorar a qualidade da Educação Básica: as estratégias do Banco Mundial IN: TOMMASI, Lívia de. et al. O Banco Mundial e as Políticas Educacionais. 2. ed., São Paulo: Cortez, 1998, p. 125-193.

\section{Como referenciar este artigo}

SOUZA, Valdirene Eliane B. de.; VAZ DE MELLO, Rita Márcia. Uma Breve reflexão do percurso das Políticas Públicas Educacionais no Brasil: em foco a formação continuada. Revista Ibero-Americana de Estudos em Educação, Araraquara, v. 14, n. 1, p. 94-107, jan./mar., 2019. E-ISSN: 1982-5587. DOI: 10.21723/riaee.v14i1.8654

Submissão: $19 / 07 / 2016$

Revisões requeridas: 20/ 05/2017

Aprovação final: 08/03/2018 